\title{
Vascular phenotypes in nonvascular subtypes of the Ehlers-Danlos syndrome: a systematic review
}

\author{
Sanne D'hondt, $\mathrm{MSc}^{1}$, Tim Van Damme, $\mathrm{MD}^{1}$ and Fransiska Malfait, MD, $\mathrm{PhD}^{1}$
}

\begin{abstract}
Purpose: Within the spectrum of the Ehlers-Danlos syndromes (EDS), vascular complications are usually associated with the vascular subtype of EDS. Vascular complications are also observed in other EDS subtypes, but the reports are anecdotal and the information is dispersed. To better document the nature of vascular complications among "nonvascular" EDS subtypes, we performed a systematic review.
\end{abstract}

Methods: We queried three databases for English-language studies from inception until May 2017, documenting both phenotypes and genotypes of patients with nonvascular EDS subtypes. The outcome included the number and nature of vascular complications.

Results: A total of 112 papers were included and data were collected from 467 patients, of whom 77 presented with a vascular phenotype. Severe complications included mainly hematomas
(53\%), frequently reported in musculocontractural and classicallike EDS; intracranial hemorrhages (18\%), with a high risk in dermatosparaxis EDS; and arterial dissections (16\%), frequently reported in kyphoscoliotic and classical EDS. Other, more minor, vascular complications were reported in cardiac-valvular, arthrochalasia, spondylodysplastic, and periodontal EDS.

Conclusion: Potentially life-threatening vascular complications are a rare but important finding in several nonvascular EDS subtypes, highlighting a need for more systematic documentation. This review will help familiarize clinicians with the spectrum of vascular complications in EDS and guide follow-up and management.

Genet Med advance online publication 5 October 2017

Key Words: connective tissue disorder; Ehlers-Danlos syndrome; nonvascular subtype; systematic review; vascular complication

\section{INTRODUCTION}

The Ehlers-Danlos syndrome (EDS) is an umbrella term for a group of clinically and genetically heterogeneous connective tissue disorders. Over the past two decades the Villefranche Nosology has been the standard for classifying EDS. It recognized six subtypes, most of which were caused by defects in the primary structure of collagen or collagen-modifying enzymes. ${ }^{1}$ Recent discoveries have, however, expanded the pathogenic spectrum to include EDS variants that are caused by defects in both noncollagenous extracellular matrix proteins and intracellular processes. ${ }^{2-10}$ This has led to an EDS reclassification: a task that was recently accomplished by an international EDS consortium. ${ }^{11}$

Skin hyperextensibility and joint hypermobility are the clinical hallmarks of EDS, but more variable signs of soft connective tissue fragility are helpful in discriminating between the different types. Historically, arterial aneurysm and dissection have been synonymous with the vascular type of EDS (vEDS). This type of EDS is characterized by the presence of a thin, translucent skin, which bruises very easily, and joint hypermobility, which is often confined to the small joints. The clinical picture is, however, dominated by a remarkable vascular fragility that leads to spontaneous rupture of blood vessel walls, often without preceding vascular dilatation or aneurysm formation. Other life-threatening complications include rupture of the gastrointestinal (GI) tract, gravid uterus, or other internal organs, such as liver or spleen. ${ }^{12}$ The calculated median survival for vEDS patients is 48 years, with most deaths resulting from arterial rupture. ${ }^{13}$ Complications are rare in childhood, but $25 \%$ will have a first complication by the age of 20 years, and more than $80 \%$ will have had at least one complication by the age of 40 years. Therapeutic interventions are limited to symptomatic measures. ${ }^{14}$ Hitherto, the only evidence-based treatment strategy has been the administration of celiprolol, a cardioselective $\beta$-blocker with $\beta 2$ agonist vasodilatory properties, which has been reported to reduce heart rate and pulsatile pressures in essential hypertension and could therefore decrease the continuous and pulsatile mechanical stress on collagen fibers within the arterial wall. ${ }^{15,16}$ vEDS is caused by heterozygous mutations in the type III procollagenencoding gene COL3A1. ${ }^{17}$ Genotype-phenotype correlations have been extensively investigated. Substitution of triple helical glycine residues and splice donor site mutations, leading to exon skipping, are generally associated with a shorter life expectancy, whereas mutations leading to COL3A1 haploinsufficiency are usually associated with a milder phenotype, a delay in the onset of complications, and a longer life expectancy. ${ }^{18,19}$

Vascular complications, including arterial aneurysms and ruptures, subcutaneous hematomas, gum bleeding, and prolonged perioperative and menstrual bleeding, have also 
been described in other, "nonvascular" subtypes of EDS. 20,21 Most of these reports are anecdotal, and the occurrence of such complications in the different EDS subtypes is not well documented. In view of the vast clinical and genetic heterogeneity of EDS, it may therefore be difficult for clinicians to predict, for a specific EDS patient, whether vascular complications should be taken into account, and how patients should be followed.

We reviewed the medical literature on EDS in a systematic manner to better document the nature of vascular complications in patients with a nonvascular EDS diagnosis confirmed via molecular testing. This review will help familiarize clinicians with the spectrum of vascular complications in nonvascular EDS subtypes as well as guide follow-up and management.

\section{MATERIALS AND METHODS}

\section{Study design}

This systematic review was designed and carried out in accordance with the guidelines of the Preferred Reporting Items for Systematic Reviews and Meta-Analyses statement for reporting systematic reviews. ${ }^{22}$

\section{Search strategy}

The aim of this study was to collect all available data on vascular complications in the nonvascular EDS subtypes described in the updated EDS classification (Table 1). We queried the PubMed and Web of Science databases, taking into account the different notations for the EDS subtypes (e.g., classic versus classical). For classical EDS (COL5A1/2), for example, the following keywords were used: Ehlers-Danlos syndrome, classic ${ }^{\star}$, COL5A1, COL5A2, Ehlers-Danlos syndrome type I, Ehlers-Danlos syndrome type II. All keywords for each EDS subtype are outlined in Table 1. Based on these keywords, search strings to query the respected databases for, for example, classical EDS (COL5A1/2) were constructed as follows: ("Ehlers-Danlos syndrome"[Title/Abstract] AND (classic $^{\star}$ [Title/Abstract] OR COL5A1[Title/Abstract] OR COL5A2[Title/Abstract])) OR "Ehlers-Danlos syndrome type I"[Title/Abstract] OR "Ehlers-Danlos syndrome type II"[Title/Abstract]. To exclude nonrelevant references, queries were restricted to "title" and "abstract" in PubMed and "topic" in Web of Science. All search strings are outlined in Supplementary Table S1 online. The Leiden Open Variation Database (http://www.lovd.nl/3.0/home) was queried for additional references. All references published from inception

Table 1 Overview of all nonvascular subtypes of the Eherls-Danlos syndrome included in this systematic review

\begin{tabular}{|c|c|c|c|c|}
\hline EDS type & IP & Gene & Protein & Keywords \\
\hline Classical (cEDS) & $A D$ & COL5A1/2 & Type $V$ collagen & $\begin{array}{l}\text { Ehlers-Danlos syndrome, classic*, COL5A1, COL5A2, } \\
\text { Ehlers-Danlos syndrome type I, Ehlers-Danlos syndrome } \\
\text { type II }\end{array}$ \\
\hline Classical-like (clEDS) & $A R$ & $T N X B$ & Tenascin X & Ehlers-Danlos syndrome, $T N X B$, tenascin-x \\
\hline Cardiac-valvular (cvEDS) & $A R$ & COL1A2 & $\begin{array}{l}\text { Type I collagen (total absence } \\
\text { of } \alpha 2 \text { chain) }\end{array}$ & Ehlers-Danlos syndrome, COL1A2 \\
\hline Dermatosparaxis (dEDS) & $A R$ & ADAMTS2 & ADAMTS2 & $\begin{array}{l}\text { Ehlers-Danlos syndrome, dermatospara*, ADAMTS2, } \\
\text { Ehlers-Danlos syndrome type VIIC }\end{array}$ \\
\hline Kyphoscoliotic (kEDS) & $A R$ & $\begin{array}{l}\text { PLOD1 } \\
\text { FKBP14 }\end{array}$ & $\begin{array}{l}\text { LH1 } \\
\text { FKBP22 }\end{array}$ & $\begin{array}{l}\text { Ehlers-Danlos syndrome, kyphoscolio*, PLOD1, } \\
\text { Ehlers-Danlos syndrome type VIA } \\
\text { Ehlers-Danlos syndrome, FKBP14 }\end{array}$ \\
\hline $\begin{array}{l}\text { Spondylodysplastic } \\
\text { (spEDS) }\end{array}$ & $A R$ & $\begin{array}{l}\text { B4GALT7 } \\
\text { B3GALT6 } \\
\text { SLC39A13 }\end{array}$ & $\begin{array}{l}\beta 4 \text { GalT7 } \\
\beta 3 \text { GalT6 } \\
\text { ZIP13 }\end{array}$ & $\begin{array}{l}\text { Ehlers-Danlos syndrome, progeroid, B4GALT7 } \\
\text { Ehlers-Danlos syndrome, progeroid, B3GALT6 Ehlers-Danlos } \\
\text { syndrome, spondylocheirodysplas*, SLC39A13 }\end{array}$ \\
\hline $\begin{array}{l}\text { Musculocontractural } \\
\text { (msEDS) }\end{array}$ & $A R$ & $\begin{array}{l}\text { CHST14 } \\
\text { DSE }\end{array}$ & $\begin{array}{l}\text { D4ST1 } \\
\text { DSE }\end{array}$ & $\begin{array}{l}\text { Ehlers-Danlos syndrome, musculocontractural, CHST14, DSE, } \\
\text { Ehlers-Danlos syndrome type VIB, adducted thumb-clubfoot } \\
\text { syndrome, Ehlers-Danlos syndrome Kosho type, } \\
\text { D4ST1-deficient Ehlers-Danlos syndrome }\end{array}$ \\
\hline Myopathic (mEDS) & $A R / A D$ & COL12A1 & Type XII collagen & Ehlers-Danlos syndrome, COL12A1 \\
\hline Periodontal (pEDS) & $A D$ & C1R/S & $\mathrm{C} 1 \mathrm{r}$ and $\mathrm{C} 1 \mathrm{~s}$ & Ehlers-Danlos syndrome, periodontal, C1R, C1S \\
\hline
\end{tabular}

$A D$, autosomal dominant; $A R$, autosomal recessive; EDS, Ehlers-Danlos syndrome; IP, inheritance pattern. 
until 31 May, 2017 were eligible for inclusion in this review. A bibliography was created using EndNote X7 (Thomson Reuters, New York, NY).

\section{Screening process and eligibility criteria}

Primary literature screening was performed by two investigators (S.D. and T.V.D.), independently, according to the following inclusion criteria: (i) population: nonvascular subtypes of EDS, (ii) language: English, (iii) papers: no short conference proceedings or meeting abstracts, and (iv) availability of the full text. Next, eligibility for inclusion in the review after full-text screening of the remaining papers was further assessed using the following criteria: descriptions of both (i) the patient's phenotype and (ii) the pathogenic genetic defect. Patients for whom only linkage to a gene or a biochemical diagnosis was demonstrated were excluded. Hypermobile EDS was also not included, since its genetic etiology remains unknown and because-prior to the updated 2017 classification on EDS ${ }^{11}$-its definition covered a broad clinical spectrum, with variable signs of connective tissue fragility that closely overlapped with joint hypermobility syndrome. The following types of studies were considered: clinical trials, case-control studies, cross-sectional studies, cohort studies, case series, and case reports published in peerreviewed scientific journals. Excluded were cell culture laboratory studies, animal studies, and reviews. Titles and abstracts were checked with regard to the predefined eligibility criteria. Abstracts with unclear methodology were included in full-text assessment to avoid exclusion of potentially relevant papers.

\section{Quality assessment}

Quality assessment tools for case series, case-control, cross-sectional, and cohort studies are available from the National Heart, Blood, and Lung Institute (Bethesda, MD) (https://www.nhlbi.nih.gov/). Quality assessment tools for case reports are available from the Joanna Briggs Institute (Adelaide, Australia) (http://joannabriggs.org/). Each study was classified into one of the following groups: (i) good if all quality criteria were judged as "present," (ii) fair if one or more key domains were "unclear," or (iii) poor if one or more key domains were "absent" (Supplementary Table S2).

\section{Data extraction and aggregation}

Data extraction and aggregation were performed by a single investigator (S.D.). Uncertainties were resolved through discussion with the principal investigator (F.M.). The following data, if available, were extracted from the included references: (i) study characteristics (authors and year of publication), (ii) patient attributes (patient and family identifiers, age at time of referral or vascular complication, and relevant comorbidities), (iii) vascular features (type and location of vascular complication, recurrence, management, and cause of death), and (iv) mutation. If a patient or family was described more than once, the most informative reference was used for data collection. The spectrum of vascular complications was further categorized into (i) hematomas, (ii) intracranial hemorrhages, (iii) arterial dissections, (iv) arterial aneurysms, (v) GI bleedings, (vi) perioperative hemorrhages, and (vii) sporadic vascular complications. The data collection on hematomas included only those that occurred spontaneously or from minor trauma or were described as severe in nature (e.g., "large," "massive," "repeated," "profuse"). Easy bruising was not included in this study for many reasons. It is often described in a nondescriptive manner, and as a symptom it is often overreported by both patients and caregivers. We therefore felt that including easy bruising would lead to an overrepresentation of vascular complications in nonvascular EDS. The primary outcome of these data-processing procedures was the derivation of the total number of nonvascular EDS patients, along with the number of patients reported with, respectively, none, one, or more than one vascular complication. The secondary outcome included the number, type, and location of reported vascular complications.

\section{RESULTS}

\section{Search results and study characteristics}

A flow diagram of the search selection process is depicted in Figure 1. Our search strategy identified 809 unique papers, 547 of which were excluded after primary screening based on title and abstract. From the remaining 262 papers selected for full-text screening, 112 papers were found to meet the predefined inclusion criteria (Figure 1). All included papers are listed in Supplementary Table S2 and a brief overview of all included studies and patients is presented in Table 2. The types of studies reported by these papers included mainly case reports $(n=51)$ and series $(n=59)$, a cross-sectional study $(n=1)$, and a cohort study $(n=1)$. There was a quality assessment of the included papers, of which 38 were classified as good, 43 as fair, and 31 as poor. None of them were rejected based on assessed quality alone, so that a large population could be obtained, based on which it is possible to draw firm conclusions. These 112 papers report on 467 patients (197 males, 238 females, and 32 not defined) from 342 unrelated families, and include 29 papers on classical EDS (cEDS; COL5A1/2: $n=25$; COL1A1 p.(Arg312Cys): $n=4),{ }^{23-51} 6$ on classical-like EDS (clEDS; TNXB), ${ }^{52-57}$ three on cardiac-valvular EDS (cvEDS; COL1A2), ${ }^{58-60}$ ten on arthrochalasia EDS (aEDS; COL1A1/2) ${ }^{61-70}$ six on dermatosparaxis EDS (dEDS; ADAMTS2), ${ }^{71-76} 22$ on kyphoscoliotic EDS (kEDS; PLOD1: $n=17$, FKBP14: $n=5$ ), ${ }^{4,77-97}$ ten on brittle cornea syndrome (BCS; ZNF469: $n=5$; PRDM5: $n=5$ ), ${ }^{2,98-106} 11$ on spondylodysplastic EDS (spEDS; B4GALT7: $n=5 ;$ B3GALT6: $n=4$; SLC39A13: $n=2),{ }^{5,8,9,107-114} 12$ on musculocontractural EDS (mcEDS; CHST14: $n=11$; DSE: $n=1), 6,7,115-124$ two on myopathic EDS (mEDS; COL12A1), ${ }^{125,126}$ and one on periodontal EDS (pEDS; C1R/ S). ${ }^{127}$ One paper that fulfilled the inclusion criteria was withheld because it contained data for a patient described more thoroughly in another paper. ${ }^{128}$ 


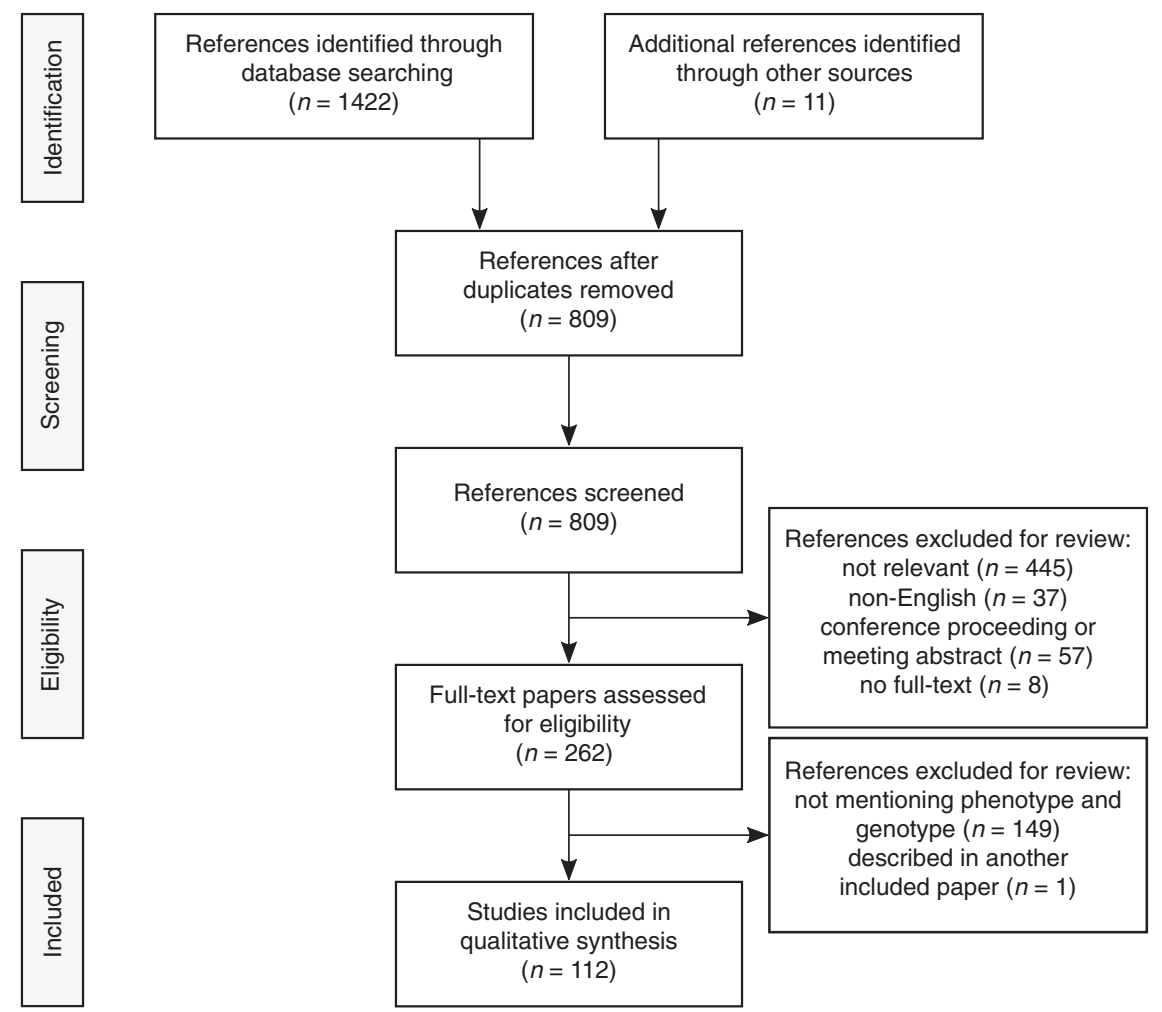

Figure 1 Flow diagram presenting the search and selection process.

\section{Nonvascular EDS with vascular complications}

Seventy-seven of 467 (17\%) individuals with nonvascular EDS (age: ranging from birth to 62 years) were reported with a total number of 100 vascular complications. Vascular complications were, in terms of percentage, most frequently reported in mcEDS-DSE (2/3, 67\%), mcEDS-CHST14 (27/43, $63 \%)$, clEDS (10/19, 53\%), cvEDS $(2 / 5,40 \%)$, dEDS (5/15, $33 \%)$, cEDS-COL1A1 (3/12, 25\%), kEDS-FKBP14 (2/10, 20\%), kEDS-PLOD1 (8/54, 15\%), spEDS-SLC39A13 (1/8, 13\%), cEDS-COL5A1/2 (12/110, 11\%), aEDS (1/17, 6\%), pEDS $(3 / 55,5 \%)$, and spEDS-B3GALT6 $(1 / 25,4 \%)$ (Figure 2a). Of these 77 individuals, $14(18 \%)$ suffered more than one complication, with an average of 1.3, ranging from one to six complications per case. This, however, corresponds to only 3\% (14/467) of all individuals included in this systematic review. The occurrence of multiple complications was reported most frequently in mcEDS-CHST14 (8/43, 19\%) (Table 3). No vascular complications were recorded in spEDS-B4GALT7, BCS and mEDS.

\section{Mortality}

Overall, death due to vascular complications was reported in eight individuals $(8 / 467,2 \%)$. In cEDS-COL5A1, three adult patients died from rupture of a large or medium-sized artery (mean age: 35 years, range $28-43$ years ${ }^{25}$ and one 9-year old patient died from multiorgan failure secondary to the rupture of an aneurysm of the superior mesenteric artery. ${ }^{31}$ One patient with cvEDS died from bleeding complications during aortic valve replacement surgery at the age of 45 years. ${ }^{60}$ In dEDS, one patient died shortly after birth from severe hemorrhage and shock. ${ }^{72}$ One patient with mcEDS-CHST14 died from a large intracerebral hemorrhage at the age of 59 years, and, finally, one with kEDS-PLOD1 died from an arterial rupture at an unspecified site at an unknown age. 89,116

\section{Vascular phenotypes and management}

To provide an overview of the type of vascular complications in nonvascular EDS patients, each reported complication $(n=100)$ was categorized as either (i) hematoma $(53 / 100$, $53 \%)$, (ii) intracranial hemorrhage (18/100,18\%), (iii) spontaneous arterial dissection $(16 / 100,16 \%)$, (iv) arterial aneurysm (5/100, 5\%), (v) GI bleeding (1/100,1\%), (vi) perioperative hemorrhage $(5 / 1005 \%)$, or (vii) sporadic vascular complication $(2 / 100,2 \%)$. An overview of the vascular phenotypes is presented in Figure 2b, and Table $\mathbf{3}$ summarizes the reported type of complications per nonvascular EDS subtype.

\section{Hematoma}

The most frequent of all vascular complications was the formation of hematomas $(53 / 100,53 \%)$, either spontaneously $(10 / 53,19 \%)$ or after minor trauma $(32 / 53,60 \%)$, such as a minor fall. They were reported primarily in mcEDS patients (25/46, 54\%) (DSE: 2/3, 67\%; CHST14: 23/43, 53\%) ${ }^{6,115-122}$ and clEDS patients $(10 / 19,53 \%),{ }^{53,55-57}$ and, to a lesser extent, in patients with dEDS $(2 / 15,13 \%)^{72,74}$ and cEDS-COL5A1 (3/110, $3 \%){ }^{34,38}$ Most hematomas were subcutaneous (41/53, 77\%), 
Table 2 Overview of all studies and patients included in this systematic review

\begin{tabular}{|c|c|c|c|c|c|}
\hline EDS subtype & Study & Quality & Gender & Age & Race/ethnicity \\
\hline cEDS (COL5A1/2) & $\begin{array}{l}\text { Case report (13), } \\
\text { case series (11), } \\
\text { cross-sectional (1) }\end{array}$ & $\begin{array}{l}\text { Good (8), fair } \\
(12) \text {, poor (5) }\end{array}$ & $\begin{array}{l}M(48), F(59), \\
\text { ND (3) }\end{array}$ & $2-67$ y & Caucasian, Turkish, Asian, black, white \\
\hline CEDS (COL1A1) & $\begin{array}{l}\text { Case report (1), } \\
\text { case series ( } 3 \text { ) }\end{array}$ & $\begin{array}{l}\text { Good (3), } \\
\text { fair (1) }\end{array}$ & $M(6), F(6)$ & $5-69$ y & Caucasian, Hispanic \\
\hline CIEDS $(T N X B)$ & $\begin{array}{l}\text { Case report ( } 3) \text {, } \\
\text { case series ( } 3 \text { ) }\end{array}$ & $\begin{array}{l}\text { Good (3), fair } \\
(2) \text {, poor (1) }\end{array}$ & $M(8), F(11)$ & $6-53$ y & Dutch \\
\hline aEDS (COL1A1/2) & $\begin{array}{l}\text { Case report (8), } \\
\text { case series ( } 2 \text { ) }\end{array}$ & $\begin{array}{l}\text { Good (4), fair } \\
\text { (4), poor (2) }\end{array}$ & $\begin{array}{l}M(4), F(12), \\
N D(1)\end{array}$ & $0-32$ y & German, Japanese, Chinese, South African, Libyan \\
\hline dEDS (ADAMTS2) & $\begin{array}{l}\text { Case report ( } 2) \\
\text { case series }(4)\end{array}$ & $\begin{array}{l}\text { Good (2), fair } \\
\text { (3), poor (1) }\end{array}$ & $M(9), F(6)$ & $0-7$ y & Caucasian, Turkish, Pakistani, Ashkenazi \\
\hline kEDS (FKBP14) & $\begin{array}{l}\text { Case report ( } 2) \text {, } \\
\text { case series ( } 3 \text { ) }\end{array}$ & $\begin{array}{l}\text { Good (3), } \\
\text { poor (2) }\end{array}$ & $M(5), F(5)$ & $2-48$ y & Caucasian, Austrian, Italian, German, French, Turkish \\
\hline BCS (ZNF469) & Case series (5) & $\begin{array}{l}\text { Good (1), fair } \\
(2) \text {, poor (2) }\end{array}$ & $M(13), F(22)$ & $0-28$ y & $\begin{array}{l}\text { British, Indian, Pakistani, Saudi Arabian, Syrian, Yemeni, } \\
\text { Palestinian, Tunisian }\end{array}$ \\
\hline $\mathrm{BCS}(P R D M 5)$ & $\begin{array}{l}\text { Case report (3), } \\
\text { case series ( } 2 \text { ) }\end{array}$ & Fair (2), poor (3) & $\begin{array}{l}M(4), F(12) \\
N D(4)\end{array}$ & $2-26$ y & Saudi Arabian, Pakistani, Yemeni, Syrian \\
\hline spEDS (B4GALT7) & $\begin{array}{l}\text { Case report ( } 2) \text {, } \\
\text { case series ( } 3 \text { ) }\end{array}$ & $\begin{array}{l}\text { Good (4), } \\
\text { fair (1) }\end{array}$ & $M(15), F(13)$ & $0-46$ y & Arab, Danish \\
\hline spEDS (B3GALT6) & $\begin{array}{l}\text { Case report (1), } \\
\text { case series ( } 3)\end{array}$ & Fair (1), poor (3) & $\begin{array}{l}M(8), F(9), \\
N D(8)\end{array}$ & $0-34$ y & $\begin{array}{l}\text { Japanese, Singaporean, Vietnamese, Italian, Canadian, } \\
\text { Brazilian, Iranian, South African }\end{array}$ \\
\hline $\mathrm{pEDS}(\mathrm{C} 1 \mathrm{R} / \mathrm{S})$ & Case series (1) & Fair (1) & $M(25), F(30)$ & ND & ND \\
\hline
\end{tabular}

BCS, brittle cornea syndrome; EDS, Ehlers-Danlos syndrome (for the definitions of the various subtypes of EDS, see Table 1); $F$, female; $M$, male; ND, not

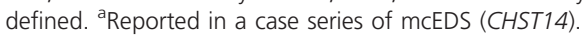

but epidural, spinal, scalp, and stomach wall hematomas were reported as well. Management was reported only in mcEDS, where some hematomas from minor trauma required transfusion $(n=7)$, surgical drainage $(n=6)$, and/or admittance to the intensive care unit $(n=3)$. One mcEDSCHST14 patient presented with a spontaneous hematoma and was treated with emergency surgical drainage and transfusion. ${ }^{115}$

\section{Intracranial hemorrhage}

The second most frequently reported vascular complication was intracranial hemorrhage $(18 / 100,18 \%)$, including 10 intracerebral, three subdural, one subarachnoid, one epidural, and three unspecified hemorrhages. dEDS denoted a high risk of intracerebral hemorrhage, affecting $20 \%$ of the patients (3/15), mostly at birth. ${ }^{73,76}$ Intracranial hemorrhages were also reported in mcEDS-CHST14 (4/43, 9\%), ${ }^{116,118,120}$ kEDSPLOD1 (4/54, 7\%), ${ }^{78,80,86,87}$ pEDS $(2 / 55,4 \%),{ }^{127}$ spEDS (2/61, 3\%) (SLC39A13: 1/8, 13\%; B3GALT6: 1/25, 4\%), and cEDS-COL5A1 $(1 / 110,1 \%){ }^{25}$

\section{Arterial dissection}

Overall, 13 patients suffered a total of 16 arterial dissections (16/100, 16\%): eight patients with cEDS (8/122, 7\%) (COL1A1: 2/12, 17\%; COL5A1: 6/110, 5\%), 25,27,33,49,50 seven patients with kEDS (7/64, 11\%) (PLOD1: 5/54, 9\%; FKBP14: $2 / 10,20 \%),{ }^{79,80,89,95,97}$ and one with cvEDS $(1 / 5,20 \%) .{ }^{60}$ Dissections occurred most frequently in medium-sized or large arteries, including the iliac, femoral, renal, celiac, hypogastric, subclavian, superior mesenteric, brachial, and coronary arteries. Aortic dissection was reported in one patient with cEDSCOL5A1. ${ }^{25}$ Data about management is limited and mostly 
a

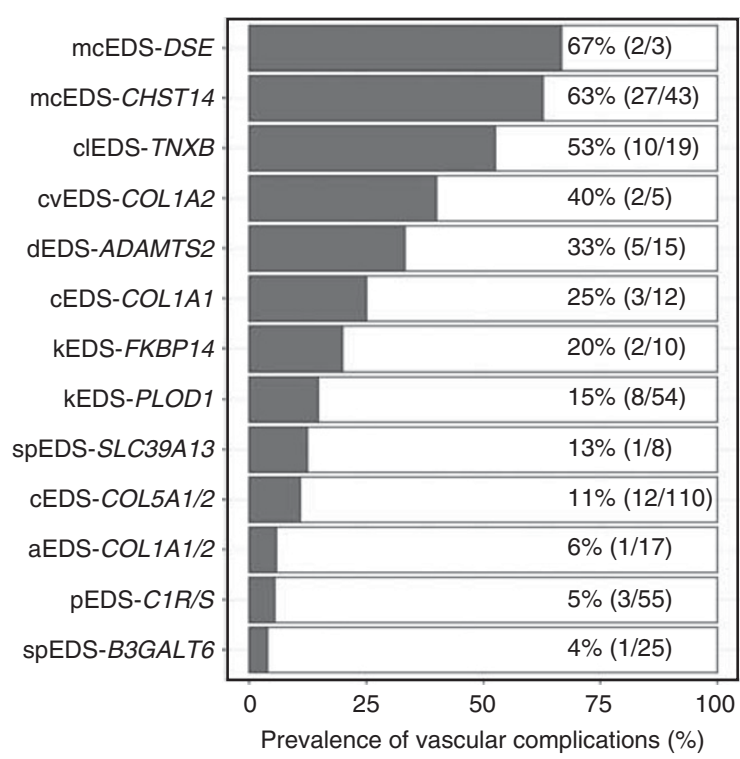

b

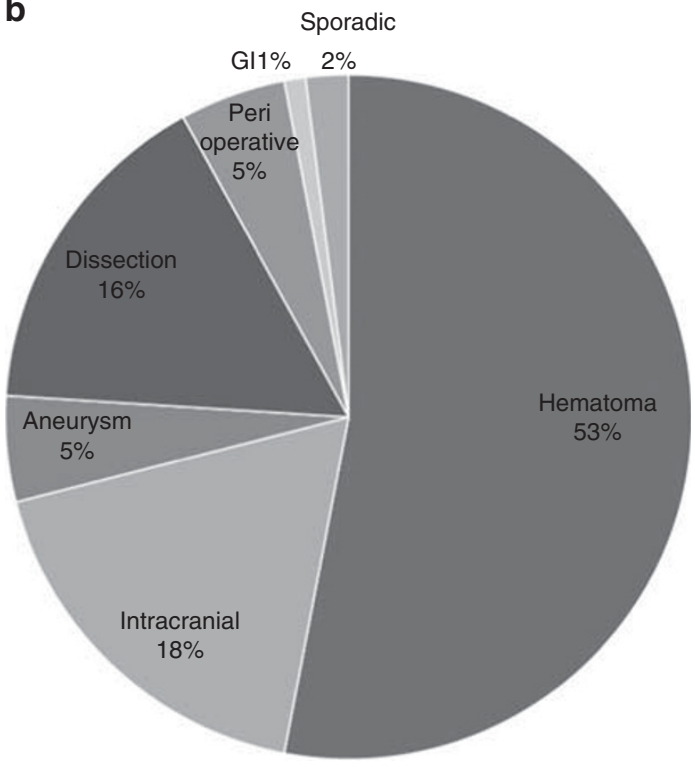

Figure 2 Vascular complications in nonvascular EDS. (a) The number of patients with vascular complications is presented for each nonvascular EDS subtype in terms of percentage. The ratios relate to the total number of patients with vascular complication(s), to the total number per subtype. (b) The number of each type of complication is presented in terms of percentage. EDS, Ehlers-Danlos syndrome (for the definitions of the various subtypes of EDS, see Table 1); GI, gastrointestinal.

anecdotal, but seven of these dissections were treated surgically and two with endovascular techniques. $25,27,49,79,95,97$

\section{Arterial aneurysm}

Arterial aneurysms were reported in five patients $(5 / 100,5 \%)$, including cEDS (4/122, 3\%; COL5A1: 3/110, 3\%; COL1A1: $1 / 12,8 \%)$ and kEDS-PLOD1 (1/54, 2\%). ${ }^{25,28,30,31,82}$ Large $(n=1)$ and medium-sized $(n=3)$ arteries were affected and aortic root dilatation was described in one cEDS patient. ${ }^{28}$ Three aneurysms were reported as having ruptured, two in connection with cEDS-COL5A1 and one with kEDS-PLOD1; they were managed using endovascular techniques. ${ }^{30,31,82}$ One patient underwent surgery twice and was followed up using regular computed tomography angiography. ${ }^{25}$

\section{Gastrointestinal bleeding}

Severe GI bleeding was reported in one cEDS-COL5A2 (1/110, 1\%) patient, who suffered a perforation of the terminal ileum at birth and was treated with an ileostomy. ${ }^{23}$ Several more common GI problems are described below.

\section{Perioperative hemorrhage}

Perioperative hemorrhage $(5 / 100,5 \%)$ was reported in two patients with mcEDS-CHST14 $(2 / 43,5 \%)$ during a laparoscopic procedure and surgery for dislocations, ${ }^{63,118,123}$ in one patient with aEDS $(1 / 18,6 \%)$ who bled excessively at surgery (unspecified), ${ }^{63}$ in one patient with pEDS $(1 / 55,2 \%)$ who had a profuse bleeding after hysterectomy, ${ }^{127}$ and in one cvEDS patient $(1 / 5,20 \%)$, who underwent aortic valve replacement surgery and died from it at the age of 45 years. ${ }^{60}$

\section{Sporadic vascular complications}

One cEDS-COL5A1 patient $(1 / 110,1 \%)$ was reported with a pulmonary artery hypoplasia, ${ }^{28}$ and one dEDS patient $(1 / 15$, $7 \%)$ presented with a pleural serohemorrhagic effusion of the left lung. ${ }^{74}$

\section{Common and aspecific vascular features}

Several vascular and bleeding complications, which are presumed to be relatively frequent in the general population, have been reported in various EDS subtypes. Since these vascular features are potentially aspecific, we listed them as complementary but did not add them to the total number of complications.

Menometrorrhagia was reported in two patients with cEDSCOL5A1 (2/65 females, $3 \%)^{28}$ and postpartum hemorrhaging was reported in one patient with aEDS (1/12 females, $8 \%)$ after the birth of each of her children and in one clEDS (1/12 females, 8\%). ${ }^{53,65}$ The severity of the latter was not described.

Minor GI bleeding was reported in two clEDS $(2 / 18$, $11 \%),{ }^{53,57}$ two dEDS $(2 / 15,13 \%),{ }^{71}$ two mcEDS-CHST14 $(2 / 43,5 \%),{ }^{115}$ and one pEDS $(1 / 55,2 \%)$ patients. ${ }^{127}$ Two dEDS patients suffered rectal prolapse with anal bleeding, ${ }^{71}$ and one clEDS patient had a gastric ulcer. ${ }^{53}$ The origin of the bleeding was not specified in the other clEDS and the pEDS patient.

Venous complications such as varicose veins and deep venous thrombosis (DVT) were reported in a number of patients. In cEDS, seven patients presented with varicose veins (7/122, 6\%; COL5A1: 4/110, 4\%; COL1A1: 3/12, 25\%) and three with a DVT $(3 / 110,3 \%){ }^{28,33,42,44,48}$ Two patients with 


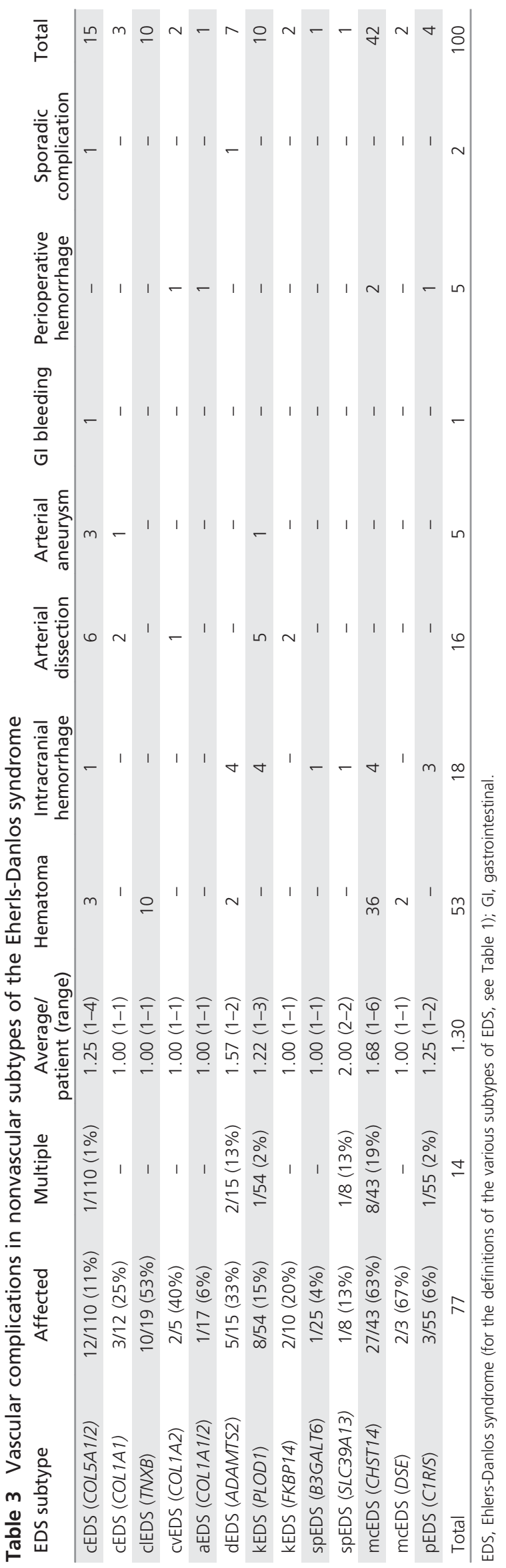

spEDS-SLC39A13 $(2 / 8,25 \%)$ presented with varicose veins, ${ }^{5}$ and one patient with kEDS-PLOD1 $(1 / 54,2 \%)$ presented with a DVT from compression stasis, which was treated by fasciotomy. ${ }^{93}$ All of these patients were over the age of 40 years, except for the kEDS-PLOD1 patient, who presented with a DVT at the age of 15 years. ${ }^{93}$

Five patients were reported with small bleedings: three of these suffered from gum bleeding (mcEDS-CHST14: 2/43, 5\%; cEDS-COL5A1: 1/110,1\%), ${ }^{28,118,123}$ and two dEDS patients suffered from epistaxis $(2 / 15,13 \%) .{ }^{71,129}$

\section{DISCUSSION}

Vascular complications are an important finding in nonvascular subtypes of EDS. Overall, 77/467 (17\%) of the patients included in this study presented with relatively severe vascular complications. In line with the clinical and genetic heterogeneity of this group of disorders, there are important differences in the number, severity, and type of complications associated with the different EDS subtypes (Table 3). Vascular complications, for example, are most frequently reported in mcEDS (CHST14/DSE) and in clEDS $(T N X B)$, being present in about two thirds and half of the patients, respectively. In contrast, to date no vascular complications have been reported for spEDS-B4GALT7, $\mathrm{BCS}$, and mEDS.

In mcEDS and clEDS, the vascular phenotype shows a large predominance of hematomas. In clEDS, hematomas are mostly spontaneous and subcutaneous, whereas in mcEDS they mostly occur after minor trauma, and also affect other locations besides subcutaneous tissues (e.g., scalp, spine, and buttock). Furthermore, these hematomas are different from the commonly reported easy bruising in EDS and the large hematomas in clEDS, because they can be severe in nature and sometimes necessitate surgery and blood transfusion. Of note, four mcEDS-CHST14 patients were reported to have intracranial bleeding, of which one person died at the age of 59 years. Therefore, this appears to be a rare but important complication of mcEDS.

cEDS, cvEDS, dEDS, and kEDS are associated with a lower, but nonetheless important risk of vascular complications. Moreover, in these subtypes, the majority of vascular complications are severe and potentially life-threatening, and include intracranial hemorrhages, arterial aneurysms, and arterial dissections. The latter complications each account for approximately $5-16 \%$ of all reported vascular complications in nonvascular EDS. Arterial aneurysms have been reported in a few patients with cEDS (COL5A1/COL1A1) and kEDS-PLOD1. Arterial dissections are most frequently reported in kEDS-FKBP14 (20\% of 10 kEDS-FKBP14 patients) and cEDS due to COL1A1 p.(Arg312Cys) (17\% of 12 cEDS-COL1A1 patients), and to a lesser extent in kEDSPLOD1 (9\% of 54 kEDS-PLOD1 patients) and cEDS-COL5A1 (5\% of 110 cEDS-COL5A1 patients). One patient with cvEDS was also reported to have an arterial dissection. As in vEDS, these aneurysms and dissections mostly affect large and medium-sized arteries, such as the iliac, femoral, renal, celiac, 
hypogastric, subclavian, superior mesenteric, brachial, and coronary arteries. Aortic dissection was reported in only one patient with cEDS-COL5A1. Arterial aneurysms and dissections have not been reported for any of the other EDS subtypes. Overall, arterial aneurysms and dissections are significantly less frequently reported than in vEDS, where such complications are reported in approximately $50 \%$ of patients. ${ }^{18,130}$

In dEDS, $25 \%$ of the patients suffered from intracranial hemorrhage, especially in the perinatal period. Intracranial hemorrhage was also reported in a range of other subtypes, including kEDS-PLOD1 (also in the perinatal period), mcEDS-CHST14, pEDS, spEDS (SLC39A13 and B3GALT6), and cEDS-COL5A1 (at ages ranging from 2 to 62 years). Despite a relatively high occurrence of these severe vascular complications, reported mortality was only $2 \%$ (8/467).

In addition to these severe and potentially life-threatening problems, several other, and often minor, bleeding manifestations, such as gynecological and GI bleedings, perioperative hemorrhage, varicose veins, DVT, gum bleeding, and epistaxis have been reported in a variety of EDS subtypes, including cEDS, clEDS, aEDS, dEDS, kEDS-PLOD1, spEDS-B3GALT6, mcEDS-CHST14, and pEDS. However, it should be noted that these bleeding manifestations are also relatively common in the general population: e.g., the estimated incidence for menometrorrhagia is $10-20 \%,{ }^{131} 3-10 \%$ for perioperative hemorrhage, ${ }^{132} 10-15 \%$ and $20-25 \%$ for varicose veins in men and women respectively. ${ }^{133}$ As such, these manifestations were not counted toward the total number of vascular complications, but were merely listed as complementary in this review.

Data on treatment and treatment outcome of arterial complications in nonvascular EDS are very limited, being reported in only 11 of 77 (14\%) patients with complications. In the case of arterial aneurysms and dissections, these patients underwent endovascular stenting $(n=5)$, classical surgery $(n=4)$, or conservative treatment $(n=2)$. It is difficult, based on the available data, to formulate guidelines for the surveillance and follow-up of arterial aneurysms in nonvascular EDS. Especially for subtypes associated with increased risk for arterial dissections and aneurysms, surveillance strategies based on noninvasive imaging, such as ultrasound, magnetic resonance angiography, and computed tomography angiography with or without venous contrast, could be recommended, as in the care guidelines for vEDS. ${ }^{134}$ Guidelines for cardiovascular care and surgery for Marfan and Loeys-Dietz syndromes, including annual cardiovascular imaging, blood pressure-lowering medication (e.g., angiotensin receptor blockers, $\beta$-blockers, or angiotensin-converting enzyme inhibitors), and surgery when approaching surgical thresholds for aortic root dimensions or acute dissection, could also be used until EDS subtype-specific recommendations are available. ${ }^{135,136}$ There are no reports about the use of celiprolol, the $\beta$-blocker that has proven to delay vascular complications in vEDS. ${ }^{15,16}$ One could argue, however, for its use in EDS subtypes with an increased risk of arterial rupture and/or aneurysm (e.g., cEDS, kEDS). Another drug that has anecdotally been reported to be useful in treating or preventing bleeding episodes and/or hematomas in several EDS subtypes, such as mcEDS, kEDS, and vEDS, is the procoagulant desmopressin (DDAVP). ${ }^{116,137,138}$

The study's inherent limitations should be taken into account when interpreting the results. First, the systematic and predefined search strategy aimed to identify all potentially relevant studies, but the risk of selection bias is not negligible. Second, extensive natural history studies on EDS are rare: the data summarized here are derived mostly from either case reports $(n=51)$ or case series $(n=59)$, which are prone to publication and selection bias, because the cases are mainly self-selected. Third, asymptomatic features (e.g., silent aneurysms) are often not actively screened for such retrospective studies. Finally, for some subtypes, such as dEDS, kEDS-FKBP14, spEDS-B4GALT7, mcEDS-DSE, and mEDS, very few patients have been reported to date. As such, it is likely that the current review is only a mere approximation of the occurrence and spectrum of vascular complications in nonvascular EDS.

In conclusion, vascular complications are important and sometimes severe in some nonvascular EDS subtypes. They are found mainly in mcEDS, clEDS, dEDS, kEDS, and cEDS. Hematomas are most frequently reported (53\%) and predominate mcEDS and clEDS. Serious, potentially lifethreatening complications such as intracranial hemorrhage, arterial aneurysms, and dissections of large and medium-sized arteries, account for approximately 18, 5 and 16\% of vascular complications, respectively, and are most frequently seen in dEDS (intracranial hemorrhage), cEDS (arterial dissections and aneurysms), and kEDS (arterial dissections). No complications were reported yet in spEDS-B4GALT7, BCS, and mEDS. Given the relatively high occurrence of vascular complications in EDS patients, referral for cardiovascular assessment and regular follow-up imaging may be required upon diagnosis, especially for cEDS, dEDS, and kEDS. If vascular complications are detected, the type and location of a complication will guide treatment options. However, to optimize management and care guidelines, future research should be focused on more systematic documentation of vascular and bleeding complications and their management in natural history studies and registries.

\section{SUPPLEMENTARY MATERIAL}

Supplementary material is linked to the online version of the paper at http://www.nature.com/gim

\section{ACKNOWLEDGMENTS}

This work was supported by Methusalem grant 08/01M01108 from Ghent University. F.M. is a fellow of the Fund for Scientific Research (FWO), Belgium.

\section{DISCLOSURE}

The authors declare no conflict of interest. 


\section{REFERENCES}

1. Beighton P, De Paepe A, Steinmann B, Tsipouras P, Wenstrup RJ. EhlersDanlos syndromes: revised nosology, Villefranche, 1997. Ehlers-Danlos National Foundation (USA) and Ehlers-Danlos Support Group (UK). Am J Med Genet. 1998;77:31-37.

2. Al-Owain M, Al-Dosari MS, Sunker A, Shuaib T, Alkuraya FS. Identification of a novel ZNF469 mutation in a large family with Ehlers-Danlos phenotype. Gene 2012;511:447-450.

3. Micheal S, Khan MI, Islam F, et al. Identification of mutations in the PRDM5 gene in brittle cornea syndrome. Cornea 2016;35:853-859.

4. Baumann M, Giunta C, Krabichler B, et al. Mutations in FKBP14 cause a variant of Ehlers-Danlos syndrome with progressive kyphoscoliosis, myopathy, and hearing loss. Am J Hum Genet. 2012;90: 201-216.

5. Fukada T, Civic N, Furuichi $T$, et al. The zinc transporter SLC39A13/ZIP13 is required for connective tissue development; its involvement in BMP/ TGF-beta signaling pathways. PLoS One 2008;3:e3642.

6. Miyake N, Kosho T, Mizumoto S, et al. Loss-of-function mutations of CHST14 in a new type of Ehlers-Danlos syndrome. Hum Mutat 2010;31: 966-974.

7. Muller T, Mizumoto S, Suresh I, et al. Loss of dermatan sulfate epimerase (DSE) function results in musculocontractural Ehlers-Danlos syndrome. Hum Mol Genet. 2013;22:3761-3772.

8. Faiyaz-Ul-Haque $\mathrm{M}$, Zaidi SH, Al-Ali $\mathrm{M}$, et al. A novel missense mutation in the galactosyltransferase-I (B4GALT7) gene in a family exhibiting facioskeletal anomalies and Ehlers-Danlos syndrome resembling the progeroid type. Am J Med Genet A. 2004;128A:39-45.

9. Malfait $F$, Kariminejad A, Van Damme $T$, et al. Defective initiation of glycosaminoglycan synthesis due to B3GALT6 mutations causes a pleiotropic Ehlers-Danlos-syndrome-like connective tissue disorder. Am J Hum Genet. 2013;92:935-945.

10. Burch GH, Gong Y, Liu W, et al. Tenascin-X deficiency is associated with Ehlers-Danlos syndrome. Nat Genet 1997;17:104-108.

11. Malfait F, Francomano C, Byers $P$, et al. The 2017 international classification of the Ehlers-Danlos syndromes. Am J Med Genet C Semin Med Genet. 2017;175:8-26.

12. Germain DP. Clinical and genetic features of vascular Ehlers-Danlos syndrome. Ann Vasc Surg. 2002;16:391-397.

13. Pepin $M$, Schwarze $U$, Superti-Furga $A$, Byers PH. Clinical and genetic features of Ehlers-Danlos syndrome type IV, the vascular type. N Engl J Med. 2000;342:673-680.

14. Beridze N, Frishman WH. Vascular Ehlers-Danlos syndrome: pathophysiology, diagnosis, and prevention and treatment of its complications. Cardiol Rev 2012;20:4-7.

15. Ong KT, Perdu J, De Backer J, et al. Effect of celiprolol on prevention of cardiovascular events in vascular Ehlers-Danlos syndrome: a prospective randomised, open, blinded-endpoints trial. Lancet 2010;376:1476-1484

16. Boutouyrie P, Bussy C, Hayoz D, et al. Local pulse pressure and regression of arterial wall hypertrophy during long-term antihypertensive treatment. Circulation 2000;101:2601-2606.

17. Pope FM, Martin GR, McKusick VA. Inheritance of Ehlers-Danlos type IV syndrome. J Med Genet 1977;14:200-204.

18. Frank $M$, Albuisson J, Ranque $B$, et al. The type of variants at the COL3A1 gene associates with the phenotype and severity of vascular EhlersDanlos syndrome. Eur J Hum Genet. 2015;23:1657-1664.

19. Leistritz DF, Pepin MG, Schwarze U, Byers PH. COL3A1 haploinsufficiency results in a variety of Ehlers-Danlos syndrome type IV with delayed onset of complications and longer life expectancy. Genet Med 2011;13: 717-722.

20. De Paepe A, Malfait F. Bleeding and bruising in patients with EhlersDanlos syndrome and other collagen vascular disorders. Br J Haematol. 2004;127:491-500.

21. Malfait F, De Paepe A. Bleeding in the heritable connective tissue disorders: mechanisms, diagnosis and treatment. Blood Rev 2009;23: 191-197.

22. Moher D, Liberati A, Tetzlaff J, Altman DG; PRISMA Group. Preferred reporting items for systematic reviews and meta-analyses: the PRISMA statement. BMJ 2009;339:b2535.

23. Watanabe $M$, Nakagawa $R$, Naruto $T$, et al. A novel missense mutation of COL5A2 in a patient with Ehlers-Danlos syndrome. Hum Genome Var. 2016;3:16030

24. Cazzato D, Castori M, Lombardi R, et al. Small fiber neuropathy is a common feature of Ehlers-Danlos syndromes. Neurology 2016;87: 155-159.
25. Monroe GR, Harakalova $M$, van der Crabben $S N$, et al. Familial Ehlers-Danlos syndrome with lethal arterial events caused by a mutation in COL5A1. Am J Med Genet A. 2015;167:1196-1203.

26. Casey MC, Robertson I, Waters PS, Hanaghan J, Khan W, Barry K. Non-operative management of diverticular perforation in a patient with suspected Ehlers-Danlos syndrome. Int I Surg Case Rep. 2014;5: 135-137.

27. Yasuda S, Imoto K, Uchida K, et al. Successful endovascular treatment of a ruptured superior mesenteric artery in a patient with EhlersDanlos syndrome. Ann Vasc Surg. 2013;27:975 e971-975.

28. Ritelli $M$, Dordoni $C$, Venturini $M$, et al. Clinical and molecular characterization of 40 patients with classic Ehlers-Danlos syndrome: identification of 18 COL5A1 and 2 COL5A2 novel mutations. Orphanet J Rare Dis. 2013:8:58

29. Morais P, Ferreira O, Magina S, et al. Classic Ehlers-Danlos syndrome: case report and brief review of literature. Acta Dermatovenerol Croat. 2013;21:118-122.

30. Mehta S, Dhar SU, Birnbaum Y. Common iliac artery aneurysm and spontaneous dissection with contralateral iatrogenic common iliac artery dissection in classic Ehlers-Danlos syndrome. Int J Angiol. 2012;21: 167-170.

31. de Leeuw K, Goorhuis JF, Tielliu IF, et al. Superior mesenteric artery aneurysm in a 9-year-old boy with classical Ehlers-Danlos syndrome. Am J Med Genet A. 2012;158A:626-629.

32. Symoens $S$, Malfait $F$, Vlummens $P$, Hermanns-Le T, Syx D, De Paepe A. A novel splice variant in the N-propeptide of COL5A1 causes an EDS phenotype with severe kyphoscoliosis and eye involvement. PloS one. 2011;6:e20121.

33. Borck G, Beighton P, Wilhelm C, Kohlhase J, Kubisch C. Arterial rupture in classic Ehlers-Danlos syndrome with COL5A1 mutation. Am J Med Genet A. 2010;152A:2090-2093.

34. Symoens $S$, Malfait F, Renard M, et al. COL5A1 signal peptide mutations interfere with protein secretion and cause classic Ehlers-Danlos syndrome. Hum Mutat 2009;30:E395-E403.

35. Malfait F, Coucke P, Symoens S, Loeys B, Nuytinck L, De Paepe A. The molecular basis of classic Ehlers-Danlos syndrome: a comprehensive study of biochemical and molecular findings in 48 unrelated patients. Hum Mutat 2005;25:28-37.

36. Pallotta R, Ehresmann T, Fusilli P, De Paepe A, Nuytinck L. Discordance between phenotypic appearance and genotypic findings in a familial case of classical Ehlers-Danlos syndrome. Am J Med Genet A. 2004;128A: 436-438.

37. Takahara $K$, Schwarze $U$, Imamura $Y$, et al. Order of intron removal influences multiple splice outcomes, including a two-exon skip, in a COL5A1 acceptor-site mutation that results in abnormal pro-alpha1(V) $\mathrm{N}$-propeptides and Ehlers-Danlos syndrome type I. Am J Hum Genet. 2002;71:451-465.

38. Giunta C, Nuytinck L, Raghunath M, Hausser I, De Paepe A, Steinmann B. Homozygous Gly530Ser substitution in COL5A1 causes mild classical Ehlers-Danlos syndrome. Am J Med Genet. 2002;109:284-290.

39. Stoler JM, Bromley B, Castro MA, Cole WG, Florer J, Wenstrup RJ. Separation of amniotic membranes after amniocentesis in an individual with the classic form of EDS and haploinsufficiency for COL5A1 expression. Am J Med Genet. 2001;101:174-177.

40. Bouma P, Cabral WA, Cole WG, Marini JC. COL5A1 exon 14 splice acceptor mutation causes a functional null allele, haploinsufficiency of alpha $1(\mathrm{~V})$ and abnormal heterotypic interstitial fibrils in Ehlers-Danlos syndrome II. J Biol Chem 2001;276:13356-13364.

41. Schwarze U, Atkinson M, Hoffman GG, Greenspan DS, Byers PH. Null alleles of the COL5A1 gene of type $V$ collagen are a cause of the classical forms of Ehlers-Danlos syndrome (types I and II). Am J Hum Genet 2000;66:1757-1765.

42. Giunta C, Steinmann B. Compound heterozygosity for a disease-causing G1489E [corrected] and disease-modifying G530S substitution in COL5A1 of a patient with the classical type of Ehlers-Danlos syndrome: an explanation of intrafamilial variability? Am J Med Genet. 2000;90: 72-79.

43. Michalickova K, Susic M, Willing MC, Wenstrup RJ, Cole WG. Mutations of the alpha2(V) chain of type $\mathrm{V}$ collagen impair matrix assembly and produce Ehlers-Danlos syndrome type I. Hum Mol Genet. 1998;7: 249-255.

44. De Paepe A, Nuytinck L, Hausser I, Anton-Lamprecht I, Naeyaert JM. Mutations in the COL5A1 gene are causal in the Ehlers-Danlos syndromes I and II. Am J Hum Genet. 1997;60:547-554. 
45. Wenstrup RJ, Langland GT, Willing MC, D'Souza VN, Cole WG. A splicejunction mutation in the region of COL5A1 that codes for the carboxyl propeptide of pro alpha $1(\mathrm{~V})$ chains results in the gravis form of the Ehlers-Danlos syndrome (type I). Hum Mol Genet. 1996;5: 1733-1736.

46. Nicholls AC, Oliver JE, McCarron S, Harrison JB, Greenspan DS, Pope FM. An exon skipping mutation of a type $V$ collagen gene (COL5A1) in EhlersDanlos syndrome. J Med Genet. 1996;33:940-946.

47. Toriello HV, Glover TW, Takahara K, et al. A translocation interrupts the COL5A1 gene in a patient with Ehlers-Danlos syndrome and hypomelanosis of Ito. Nat Genet. 1996;13:361-365.

48. Colombi M, Dordoni C, Venturini M, Zanca A, Calzavara-Pinton P, Ritelli M. Delineation of Ehlers-Danlos syndrome phenotype due to the c.934C > T, p.(Arg312Cys) mutation in COL1A1: report on a threegeneration family without cardiovascular events, and literature review. Am J Med Genet A. 2017;173:524-530.

49. Gaines R, Tinkle BT, Halandras PM, Al-Nouri O, Crisostomo P, Cho JS. Spontaneous ruptured dissection of the right common iliac artery in a patient with classic Ehlers-Danlos syndrome phenotype. Ann Vasc Surg. 2015;29:595 e511-594.

50. Malfait F, Symoens S, De Backer J, et al. Three arginine to cysteine substitutions in the pro-alpha (I)-collagen chain cause Ehlers-Danlos syndrome with a propensity to arterial rupture in early adulthood. Hum Mutat. 2007;28:387-395.

51. Nuytinck L, Freund M, Lagae L, Pierard GE, Hermanns-Le T, De Paepe A. Classical Ehlers-Danlos syndrome caused by a mutation in type I collagen. Am J Hum Genet. 2000;66:1398-1402.

52. Kaufman CS, Butler MG. Mutation in TNXB gene causes moderate to severe Ehlers-Danlos syndrome. World J Med Genet. 2016;6:17-21.

53. Demirdas S, Dulfer E, Robert $L$, et al. Recognizing the tenascin-X deficient type of Ehlers-Danlos syndrome: a cross-sectional study in 17 patients. Clin Genet 2016;91:411-425.

54. Chen W, Perritt AF, Morissette R, et al. Ehlers-Danlos syndrome caused by biallelic TNXB variants in patients with congenital adrenal hyperplasia. Human Mutat 2016;37:893-897.

55. Sakiyama T, Kubo A, Sasaki T, et al. Recurrent gastrointestinal perforation in a patient with Ehlers-Danlos syndrome due to tenascin-X deficiency. J Dermatol 2015;42:511-514.

56. Penisson-Besnier I, Allamand V, Beurrier P, et al. Compound heterozygous mutations of the TNXB gene cause primary myopathy. Neuromuscul Disord. 2013;23:664-669.

57. Schalkwijk J, Zweers MC, Steijlen PM, et al. A recessive form of the Ehlers-Danlos syndrome caused by tenascin-X deficiency. N Engl J Med. 2001;345:1167-1175.

58. Melis D, Cappuccio G, Ginocchio VM, et al. Cardiac valve disease: an unreported feature in Ehlers Danlos syndrome arthrocalasia type? Ital J Pediatr. 2012;38:65

59. Malfait F, Symoens S, Coucke P, Nunes L, De Almeida S, De Paepe A. Total absence of the alpha2(I) chain of collagen type I causes a rare form of Ehlers-Danlos syndrome with hypermobility and propensity to cardiac valvular problems. J Med Genet. 2006;43:e36.

60. Schwarze U, Hata R, McKusick VA, et al. Rare autosomal recessive cardiac valvular form of Ehlers-Danlos syndrome results from mutations in the COL1A2 gene that activate the nonsense-mediated RNA decay pathway. Am J Hum Genet. 2004;74:917-930.

61. Hatamochi A, Hamada T, Yoshino M, Hashimoto T. The first Japanese case of the arthrochalasia type of Ehlers-Danlos syndrome with COL1A2 gene mutation. Gene 2014;538:199-203.

62. Giunta C, Superti-Furga A, Spranger S, Cole WG, Steinmann B. EhlersDanlos syndrome type VII: clinical features and molecular defects. J Bone Joint Surg Am 1999;81:225-238.

63. Byers PH, Duvic M, Atkinson M, et al. Ehlers-Danlos syndrome type VIIA and VIIB result from splice-junction mutations or genomic deletions that involve exon 6 in the COL1A1 and COL1A2 genes of type I collagen. Am J Med Genet. 1997:72:94-105.

64. Ho KK, Kong RY, Kuffner T, Hsu LH, Ma L, Cheah KS. Further evidence that the failure to cleave the aminopropeptide of type I procollagen is the cause of Ehlers-Danlos syndrome type VII. Hum Mut 1994;3:358-364.

65. Carr AJ, Chiodo AA, Hilton JM, Chow CW, Hockey A, Cole WG. The clinical features of Ehlers-Danlos syndrome type VIIB resulting from a base substitution at the splice acceptor site of intron 5 of the COL1A2 gene. J Med Genet. 1994;31:306-311.

66. Chiodo AA, Hockey A, Cole WG. A base substitution at the splice acceptor site of intron 5 of the COL1A2 gene activates a cryptic splice site within exon 6 and generates abnormal type I procollagen in a patient with Ehlers-Danlos syndrome type VII. J Biol Chem. 1992;267: 6361-6369.

67. Watson RB, Wallis GA, Holmes DF, Viljoen D, Byers PH, Kadler KE. Ehlers Danlos syndrome type VIIB. Incomplete cleavage of abnormal type I procollagen by $\mathrm{N}$-proteinase in vitro results in the formation of copolymers of collagen and partially cleaved pNcollagen that are near circular in cross-section. J Biol Chem. 1992;267:9093-9100.

68. Vasan NS, Kuivaniemi $H$, Vogel BE, et al. A mutation in the pro alpha 2(I) gene (COL1A2) for type I procollagen in Ehlers-Danlos syndrome type VII: evidence suggesting that skipping of exon 6 in RNA splicing may be a common cause of the phenotype. Am J Hum Genet. 1991;48:305-317.

69. D'Alessio M, Ramirez F, Blumberg BD, et al. Characterization of a COL1A1 splicing defect in a case of Ehlers-Danlos syndrome type VII: further evidence of molecular homogeneity. Am J Hum Genet. 1991;49: 400-406.

70. Wirtz MK, Glanville RW, Steinmann B, Rao VH, Hollister DW. EhlersDanlos syndrome type VIIB. Deletion of 18 amino acids comprising the N-telopeptide region of a pro-alpha 2(I) chain. J Biol Chem. 1987;262: 16376-16385

71. Van Damme T, Colige A, Syx D, et al. Expanding the clinical and mutational spectrum of the Ehlers-Danlos syndrome, dermatosparaxis type. Genet Med. 2016;18:882-891.

72. Solomons J, Coucke P, Symoens S, et al. Dermatosparaxis (Ehlers-Danlos type VIIC): prenatal diagnosis following a previous pregnancy with unexpected skull fractures at delivery. Am J Med Genet A. 2013;161A: $1122-1125$

73. Bar-Yosef O, Polak-Charcon S, Hoffman C, Feldman ZP, Frydman M, Kuint J. Multiple congenital skull fractures as a presentation of EhlersDanlos syndrome type VIIC. Am J Med Genet A. 2008;146A:3054-3057.

74. Malfait F, De Coster P, Hausser I, et al. The natural history, including orofacial features of three patients with Ehlers-Danlos syndrome, dermatosparaxis type (EDS type VIIC). Am J Med Genet A. 2004;131: 18-28.

75. Colige A, Nuytinck L, Hausser I, et al. Novel types of mutation responsible for the dermatosparactic type of Ehlers-Danlos syndrome (Type VIIC) and common polymorphisms in the ADAMTS2 gene. J Invest Dermatol. 2004; 123:656-663.

76. Colige A, Sieron AL, Li SW, et al. Human Ehlers-Danlos syndrome type VII $C$ and bovine dermatosparaxis are caused by mutations in the procollagen I N-proteinase gene. Am J Hum Genet. 1999;65:308-317.

77. Abdalla EM, Rohrbach M, Burer C, et al. Kyphoscoliotic type of EhlersDanlos Syndrome (EDS VIA) in six Egyptian patients presenting with a homogeneous clinical phenotype. Eur J Pediatr. 2015;174:105-112.

78. Tosun A, Kurtgoz S, Dursun S, Bozkurt G. A case of Ehlers-Danlos syndrome type VIA with a novel PLOD1 gene mutation. Pediatr Neurol 2014;51:566-569.

79. Gok E, Goksel OS, Alpagut U, Dayioglu E. Spontaneous brachial pseudoaneurysm in a 12-year-old with kyphoscoliosis-type Ehlers-Danlos syndrome. Eur J Vasc Endovasc Surg. 2012;44:482-484.

80. Rohrbach $M$, Vandersteen $A$, Yis $U$, et al. Phenotypic variability of the kyphoscoliotic type of Ehlers-Danlos syndrome (EDS VIA): clinical, molecular and biochemical delineation. Orphanet J Rare Dis. 2011;6:46.

81. Kariminejad A, Bozorgmehr B, Khatami A, Kariminejad MH, Giunta C, Steinmann B. Ehlers-Danlos syndrome type VI in a 17-year-old Iranian boy with severe muscular weakness-a diagnostic challenge? Iran J Pediatr. 2010;20:358-362.

82. Voermans NC, Bonnemann CG, Lammens M, van Engelen BG, Hamel $B C$. Myopathy and polyneuropathy in an adolescent with the kyphoscoliotic type of Ehlers-Danlos syndrome. Am J Med Genet A. 2009:149A:2311-2316.

83. Yis U, Dirik E, Chambaz C, Steinmann B, Giunta C. Differential diagnosis of muscular hypotonia in infants: the kyphoscoliotic type of Ehlers-Danlos syndrome (EDS VI). Neuromuscul Disord. 2008;18:210-214.

84. Salavoura K, Valari M, Kolialexi A, Mavrou A, Kitsiou S. A case of Ehlers Danlos syndrome type VI. Genet Couns 2006;17:291-294.

85. Giunta C, Randolph A, Al-Gazali LI, Brunner HG, Kraenzlin ME, Steinmann B. Nevo syndrome is allelic to the kyphoscoliotic type of the Ehlers-Danlos syndrome (EDS VIA). Am J Med Genet A. 2005;133A: 158-164.

86. Giunta C, Randolph A, Steinmann B. Mutation analysis of the PLOD1 gene: an efficient multistep approach to the molecular diagnosis of the kyphoscoliotic type of Ehlers-Danlos syndrome (EDS VIA). Mol Genet Metab. 2005;86:269-276. 
87. Brunk I, Stover B, Ikonomidou C, Brinckmann J, Neumann LM. EhlersDanlos syndrome type $\mathrm{VI}$ with cystic malformations of the meninges in a 7-year-old girl. Eur J Pediatr. 2004;163:214-217.

88. Eyre D, Shao P, Weis MA, Steinmann B. The kyphoscoliotic type of EhlersDanlos syndrome (type $\mathrm{VI}$ ): differential effects on the hydroxylation of lysine in collagens I and II revealed by analysis of cross-linked telopeptides from urine. Mol Genet Metab. 2002;76:211-216.

89. Yeowell HN, Allen JD, Walker LC, Overstreet MA, Murad S, Thai SF. Deletion of cysteine 369 in lysyl hydroxylase 1 eliminates enzyme activity and causes Ehlers-Danlos syndrome type VI. Matrix Biol 2000;19: 37-46.

90. Yeowell HN, Walker LC, Farmer B, Heikkinen J, Myllyla R. Mutational analysis of the lysyl hydroxylase 1 gene (PLOD) in six unrelated patients with Ehlers-Danlos syndrome type VI: prenatal exclusion of this disorder in one family. Hum Mutat. 2000;16:90.

91. Walker LC, Marini JC, Grange DK, Filie J, Yeowell HN. A patient with Ehlers-Danlos syndrome type $\mathrm{Vl}$ is homozygous for a premature termination codon in exon 14 of the lysyl hydroxylase 1 gene. Mol Genet Metab. 1999:67:74-82.

92. Pousi B, Hautala T, Heikkinen J, Pajunen L, Kivirikko KI, Myllyla R. Alu-Alu recombination results in a duplication of seven exons in the lysyl hydroxylase gene in a patient with the type $\mathrm{VI}$ variant of Ehlers-Danlos syndrome. Am J Hum Genet. 1994;55:899-906.

93. Dembure PP, Janko AR, Priest JH, Elsas $\sqcup$. Ascorbate regulation of collagen biosynthesis in Ehlers-Danlos syndrome, type VI. Metabolism 1987;36:687-691.

94. Bursztejn AC, Baumann M, Lipsker D. Ehlers-Danlos syndrome related to FKBP14 mutations: detailed cutaneous phenotype. Clin Exp Dermatol. 2017:42:64-67.

95. Dordoni C, Ciaccio C, Venturini M, Calzavara-Pinton P, Ritelli M, Colombi M. Further delineation of FKBP14-related Ehlers-Danlos syndrome: A patient with early vascular complications and nonprogressive kyphoscoliosis, and literature review. Am J Med Genet A. 2016;170:2031-2038.

96. Aldeeri AA, Alazami AM, Hijazi H, Alzahrani F, Alkuraya FS. Excessively redundant umbilical skin as a potential early clinical feature of Morquio syndrome and FKBP14-related Ehlers-Danlos syndrome. Clin Genet 2014;86:469-472.

97. Murray ML, Yang M, Fauth C, Byers PH. FKBP14-related Ehlers-Danlos syndrome: expansion of the phenotype to include vascular complications. Am J Med Genet A. 2014;164A:1750-1755.

98. Rohrbach M, Spencer HL, Porter LF, et al. ZNF469 frequently mutated in the brittle cornea syndrome (BCS) is a single exon gene possibly regulating the expression of several extracellular matrix components. Mol Genet Metab. 2013;109:289-295.

99. Khan AO, Aldahmesh MA, Mohamed JN, Alkuraya FS. Blue sclera with and without corneal fragility (brittle cornea syndrome) in a consanguineous family harboring ZNF469 mutation (p.E1392X). Arch Ophthalmol. 2010;128:1376-1379.

100. Christensen AE, Knappskog PM, Midtbo M, et al. Brittle cornea syndrome associated with a missense mutation in the zinc-finger 469 gene. Invest Ophthalmol Vis Sci. 2010:51:47-52.

101. Abu A, Frydman M, Marek D, et al. Deleterious mutations in the ZincFinger 469 gene cause brittle cornea syndrome. Am J Hum Genet. 2008;82:1217-1222.

102. Porter LF, Galli GG, Williamson S, et al. A role for repressive complexes and H3K9 di-methylation in PRDM5-associated brittle cornea syndrome. Hum Mol Genet. 2015;24:6565-6579.

103. Porter $L F$, Gallego-Pinazo $R$, Keeling $C L$, et al. Bruch's membrane abnormalities in PRDM5-related brittle cornea syndrome. Orphanet J Rare Dis. 2015:10:145

104. Avgitidou G, Siebelmann S, Bachmann B, Kohlhase J, Heindl LM, Cursiefen C. Brittle cornea syndrome: case report with novel mutation in the PRDM5 gene and review of the literature. Case Rep Ophthalmol Med. 2015:2015:637084.

105. Aldahmesh MA, Mohamed JY, Alkuraya FS. A novel mutation in PRDM5 in brittle cornea syndrome. Clin Genet 2012;81:198-199.

106. Burkitt Wright EM, Spencer HL, Daly SB, et al. Mutations in PRDM5 in brittle cornea syndrome identify a pathway regulating extracellular matrix development and maintenance. Am J Hum Genet. 2011;88: 767-777.

107. Salter CG, Davies JH, Moon RJ, et al. Further defining the phenotypic spectrum of B4GALT7 mutations. Am J Med Genet A. 2016;170; $1556-1563$.
108. Cartault $F$, Munier $P$, Jacquemont $M L$, et al. Expanding the clinical spectrum of B4GALT7 deficiency: homozygous p.R270C mutation with founder effect causes Larsen of Reunion Island syndrome. Eur J Hum Genet. 2015;23:49-53.

109. Guo MH, Stoler J, Lui J, et al. Redefining the progeroid form of EhlersDanlos syndrome: report of the fourth patient with B4GALT7 deficiency and review of the literature. Am J Med Genet A. 2013;161A: 2519-2527.

110. Okajima T, Fukumoto S, Furukawa K, Urano T. Molecular basis for the progeroid variant of Ehlers-Danlos syndrome. Identification and characterization of two mutations in galactosyltransferase I gene. J Biol Chem. 1999;274:28841-28844.

111. Vorster AA, Beighton P, Ramesar RS. Spondyloepimetaphyseal dysplasia with joint laxity (Beighton type); mutation analysis in eight affected South African families. Clin Genet 2015;87:492-495.

112. Sellars EA, Bosanko KA, Lepard T, Garnica A, Schaefer GB. A newborn with complex skeletal abnormalities, joint contractures, and bilateral corneal clouding with sclerocornea. Semin Pediatr Neurol. 2014;21:84-87.

113. Nakajima M, Mizumoto S, Miyake N, et al. Mutations in B3GALT6, which encodes a glycosaminoglycan linker region enzyme, cause a spectrum of skeletal and connective tissue disorders. Am J Hum Genet. 2013;92:927-934.

114. Giunta C, Elcioglu NH, Albrecht B, et al. Spondylocheiro dysplastic form of the Ehlers-Danlos syndrome - an autosomal-recessive entity caused by mutations in the zinc transporter gene SLC39A13. Am J Hum Genet. 2008;82:1290-1305.

115. Mizumoto S, Kosho T, Hatamochi A, et al. Defect in dermatan sulfate in urine of patients with Ehlers-Danlos syndrome caused by a CHST14/ D4ST1 deficiency. Clin Biochem. 2017;50:670-677.

116. Janecke $A R$, Li B, Boehm $M$, et al. The phenotype of the musculocontractural type of Ehlers-Danlos syndrome due to CHST14 mutations. Am J Med Genet A. 2016;170A:103-115.

117. Mochida K, Amano M, Miyake N, Matsumoto N, Hatamochi A, Kosho T. Dermatan 4-O-sulfotransferase 1-deficient Ehlers-Danlos syndrome complicated by a large subcutaneous hematoma on the back. J Dermatol 2016:43:832-833.

118. Syx D, Van Damme T, Symoens S, et al. Genetic heterogeneity and clinical variability in musculocontractural Ehlers-Danlos syndrome caused by impaired dermatan sulfate biosynthesis. Hum Mutat 2015;36: 535-547.

119. Winters KA, Jiang Z, Xu W, et al. Re-assigned diagnosis of D4ST1deficient Ehlers-Danlos syndrome (adducted thumb-clubfoot syndrome) after initial diagnosis of Marden-Walker syndrome. Am J Med Genet A. 2012;158A:2935-2940.

120. Mendoza-Londono R, Chitayat D, Kahr WH, et al. Extracellular matrix and platelet function in patients with musculocontractural Ehlers-Danlos syndrome caused by mutations in the CHST14 gene. Am J Med Genet A. 2012;158A:1344-1354.

121. Voermans NC, Kempers M, Lammens M, et al. Myopathy in a 20-yearold female patient with D4ST-1 deficient Ehlers-Danlos syndrome due to a homozygous CHST14 mutation. Am J Med Genet A. 2012;158A: 850-855.

122. Shimizu K, Okamoto N, Miyake N, et al. Delineation of dermatan 4-Osulfotransferase 1 deficient Ehlers-Danlos syndrome: observation of two additional patients and comprehensive review of 20 reported patients. Am J Med Genet A. 2011;155A:1949-1958.

123. Malfait $F$, Syx $D$, Vlummens $P$, et al. Musculocontractural Ehlers-Danlos Syndrome (former EDS type VIB) and adducted thumb clubfoot syndrome (ATCS) represent a single clinical entity caused by mutations in the dermatan-4-sulfotransferase 1 encoding CHST14 gene. Hum Mutat 2010;31:1233-1239.

124. Dundar M, Muller T, Zhang Q, et al. Loss of dermatan-4-sulfotransferase 1 function results in adducted thumb-clubfoot syndrome. Am J Hum Genet. 2009;85:873-882.

125. Zou Y, Zwolanek D, Izu Y, et al. Recessive and dominant mutations in COL12A1 cause a novel EDS/myopathy overlap syndrome in humans and mice. Hum Mol Genet. 2014;23:2339-2352.

126. Hicks D, Farsani GT, Laval S, et al. Mutations in the collagen XII gene define a new form of extracellular matrix-related myopathy. Hum Mol Genet. 2014;23:2353-2363.

127. Kapferer-Seebacher I, Pepin M, Werner R, et al. Periodontal EhlersDanlos syndrome is caused by mutations in C1R and C1S, which encode subcomponents $\mathrm{C} 1 \mathrm{r}$ and $\mathrm{C} 1 \mathrm{~s}$ of complement. Am J Hum Genet. 2016;99:1005-1014. 
128. Gotte M, Kresse H. Defective glycosaminoglycan substitution of decorin in a patient with progeroid syndrome is a direct consequence of two point mutations in the galactosyltransferase I (beta4GalT-7) gene. Biochem Genet 2005;43:65-77.

129. Fergelot P, Coupry I, Rooryck C, et al. Atypical male and female presentations of FLNA-related periventricular nodular heterotopia. Eur J Med Genet. 2012;55:313-318.

130. Pepin MG, Schwarze U, Rice KM, Liu M, Leistritz D, Byers PH. Survival is affected by mutation type and molecular mechanism in vascular EhlersDanlos syndrome (EDS type IV). Genet Med 2014;16:881-888.

131. El-Hemaidi I, Gharaibeh A, Shehata H. Menorrhagia and bleeding disorders. Curr Opin Obstet Gynecol. 2007;19:513-520.

132. Knight M, Callaghan WM, Berg C, et al. Trends in postpartum hemorrhage in high resource countries: a review and recommendations from the International Postpartum Hemorrhage Collaborative Group. BMC Pregnancy Childbirth. 2009;9:55.

133. Callam MJ. Epidemiology of varicose veins. Br J Surg. 1994;81:167-173.

134. Pepin MG, Murray ML, Byers PH. Vascular Ehlers-Danlos syndrome. In: Pagon RA, Adam MP, Ardinger HH, et al. (eds.). GeneReviews. University of Washington: Seattle, WA, 1993.

135. Loeys BL, Dietz HC, Braverman AC, et al. The revised Ghent nosology for the Marfan syndrome. J Med Genet. 2010;47:476-485.

136. MacCarrick G, Black 3rd JH, , Bowdin S, et al. Loeys-Dietz syndrome: a primer for diagnosis and management. Genet Med 2014;16:576-587.
137. Mast KJ, Nunes ME, Ruymann FB, Kerlin BA. Desmopressin responsiveness in children with Ehlers-Danlos syndrome associated bleeding symptoms. Br J Haematol. 2009;144:230-233.

138. Stine KC, Becton DL. DDAVP therapy controls bleeding in Ehlers-Danlos syndrome. J Pediatr Hematol Oncol. 1997;19:156-158.

$(1) \odot$ This work is licensed under a Creative Commons

Attribution-NonCommercial-NoDerivs

International License. The images or other third party material in this article are included in the article's Creative Commons license, unless indicated otherwise in the credit line; if the material is not included under the Creative Commons license, users will need to obtain permission from the license holder to reproduce the material. To view a copy of this license, visit http://creativecommons.org/licenses/ by-nc-nd/4.0/

(C) The Author(s) 2018 